\title{
A Randomized Controlled Trial of Topical Application of Tranexamic Acid in Patients with Thoracolumbar Spine Trauma Undergoing Long- Segment Instrumented Posterior Spinal Fusion
}

\author{
Weera Sudprasert, Terdpong Tanaviriyachai, Kongtush Choovongkomol, \\ Sarut Jongkittanakul, Urawit Piyapromdee \\ Department of Orthopedic Surgery, Maharat Nakhon Ratchasima Hospital, Nakhon Ratchasima, Thailand
}

\begin{abstract}
Study Design: Prospective, randomized controlled trial.
Purpose: To evaluate the effect of topically applied tranexamic acid (TXA) on postoperative blood loss of neurologically intact patients with thoracolumbar spine trauma.

Overview of Literature: Few articles exist regarding the use of topical TXA for postoperative bleeding and blood transfusion in spinal surgery.

Methods: A total of 57 patients were operated on with long-segment instrumented fusion without decompression. In 29 patients, a solution containing $1 \mathrm{~g}$ of TXA $(20 \mathrm{~mL})$ was applied to the site of surgery via a drain tube after the spinal fascia was closed, and then the drain was clamped for 2 hours. The 28 patients in the control group received the same volume of normal saline, and clamping was performed using the same technique. The groups were compared for postoperative packed red cells (PRC) transfusion rate and drainage volume.

Results: The rate of postoperative PRC transfusion was significantly lower in the topical TXA group than in the control group (13.8\% vs. $39.3 \%$; relative risk, $0.35 ; 95 \%$ confidence interval, 0.13 to $0.97 ; p=0.03$ ). The mean total drainage volume was significantly lower in the topical TXA group than in the control group $(246.7 \pm 125 \mathrm{~mL}$ vs. $445.7 \pm 211.1 \mathrm{~mL}, p<0.01)$. No adverse events or complications were recorded in any patient during treatment over a mean follow-up period of 27.5 months.

Conclusions: The use of topically administered $1 \mathrm{~g}$ TXA in thoracic and lumbar spinal trauma cases effectively decreased postoperative transfusion requirements and minimized postoperative blood loss, as determined by the total drainage volume.
\end{abstract}

Keywords: Tranexamic acid; Postoperative hemorrhage; Spinal fusion; Pedicle screws; Spinal injuries

\section{Introduction}

Thoracic and lumbar spine trauma (TLST) usually results from a high-energy injury and is frequently associated with chest and abdominal injuries [1]. Mechanically unstable spinal injuries are commonly noted following severe spine trauma, and they often require surgical stabilization due to a high risk of neurological decline [2]. Operative

\footnotetext{
Received Jun 2, 2018; Revised Jul 7, 2018; Accepted Jul 25, 2018

Corresponding author: Weera Sudprasert

Department of Orthopedic Surgery, Maharat Nakhon Ratchasima Hospital, Mueang, Nakhon Ratchasima, 30000, Thailand

Tel: +6644235529, Fax: +6644259677, E-mail: weespine@gmail.com
} 
intervention for patients without neurological deficits should be considered if the Thoracolumbar Injury Classification and Severity (TLICS) score exceeds 4 points $[3,4]$. Multilevel spinal fusions require a longer operative time, with significant soft tissue stripping as well as blood loss, which frequently leads to allogeneic blood transfusion [5]. In particular, the economic disadvantage associated with significant iatrogenic blood loss contributes to the direct costs of blood product usage. Moreover, indirect costs, including those associated with prolonged hospitalization, are often involved in the management of this complication [6-8].

Several interventions have been used to reduce surgical blood loss and the need for transfusion, including acute normovolemic hemodilution and various blood salvaging techniques $[7,8]$. Additionally, antifibrinolytic agents have been used in various studies to control acute hemorrhage and decrease transfusion requirements in patients undergoing surgical treatment $[5,7,9]$. Intravenous administration of tranexamic acid (TXA) not only reduces perioperative hemorrhage, but also minimizes the need for blood transfusion by one-third in several clinical settings, including major surgery [9]. This is especially important in multilevel spinal fusion procedures with instrumentation, which often require postoperative blood transfusion [10]. Even though intravenous TXA has been shown to reduce excessive postoperative bleeding, it is unclear whether the effects of this drug can be escalated, potentially resulting in thromboembolic events and cardiovascular complications (e.g., pulmonary embolism, deep venous thrombosis, and myocardial infarction) [11]. Topical TXA might enhance patient safety, as similar effects via an intravenous route were reported in another study [12].

The present study examined different techniques of topical TXA application in spinal surgery compared with normal saline placebo. The purpose was to evaluate the effect of topically applied $1 \mathrm{~g}$ TXA on postoperative packed red cells (PRC) transfusion and blood loss in neurologically intact patients with TLST.

\section{Materials and Methods}

\section{Patient sample and data collection}

After ethical approval by the Institutional Review Board of Maharat Nakhon Ratchasima Hospital, patients with TLST (clinically and radiographically confirmed TLICS score $\geq 5$ points) were evaluated at the Department of Orthopedic Surgery between May 2015 and September 2016. All patients with spinal trauma who were admitted to the Maharat Nakhon Ratchasima Hospital during this period were consecutively assessed for inclusion and exclusion criteria (Table 1). Neurological function was scored according to the standard protocol established by the American Spinal Injury Association. Additional clinical parameters collected included the patient's age, sex, body mass index, TLICS score, mechanism of injury, and American Society of Anesthesiologists physical status and radiographic features. Before study enrollment, each patient underwent plain radiography of the affected regions in the anteroposterior and lateral projections. All patients also underwent a preoperative computed tomographic

Table 1. The inclusion and exclusion criteria

\begin{tabular}{|c|c|}
\hline Inclusion criteria & Exclusion criteria \\
\hline $\begin{array}{l}\text { Men and women, } 18 \text { to } 70 \text { years of age with injuries involving the } \\
\text { thoracic or lumbar spine (Thoracolumbar Injury Classification and } \\
\text { Severity score } \geq 5 \text { ) undergoing long-segment instrumented poste- } \\
\text { rior spinal fusion with local autologous bone graft } \\
\text { No neurological deficits } \\
\text { American Society of Anesthesiologists physical status class I, II, or III }\end{array}$ & $\begin{array}{l}\text { Renal insufficiency } \\
\text { History of thromboembolic events (e.g., pulmonary embolism, embolic } \\
\text { stroke, and deep venous thrombosis) } \\
\text { History of significant cardiovascular diseases (e.g., unstable angina, } \\
\text { recent myocardial infarction, significant arrhythmia, and uncontrolled } \\
\text { hypertension) } \\
\text { History of acquired defective color vision } \\
\text { Coagulation disorder } \\
\text { Gross hematuria or microhematuria } \\
\text { Displaced laminar fracture on computed tomography axial section that } \\
\text { might be associated with dural tears } \\
\text { Allergy to tranexamic acid } \\
\text { Take aspirin or nonsteroidal anti-inflammatory drugs within a week before } \\
\text { randomization and during the hospitalization }\end{array}$ \\
\hline
\end{tabular}


scan of the thoracic and lumbar areas with multiplanar reconstructions. The patients were educated about the symptoms of thrombotic and embolic disorders as well as treatment-related side effects from the use of TXA. The procedure was explained to all participants, who gave their voluntary written informed consent. The surgeons and participants did not know to which group each patient belonged.

The study was conducted in accordance with the consolidated standards of reporting trials statement for randomized controlled trials. This was a double-blinded, prospective, randomized, controlled clinical trial to compare topically applied TXA and placebo in TLST patients without neurological deficits. Enrolled participants were assigned to one of the two treatment groups at a 1:1 ratio using blocked randomization. A four-number-per block randomization was performed using random numbers generated by statistical software, and the allocations were concealed in opaque envelopes. According to the results of a previous retrospective study [13], a sample size of at least 28 patients per group was needed to detect a reduction in postoperative transfusion rate from $44.7 \%$ in the matched control group to $11.4 \%$ in the deferred treatment group with a two-sided significance level of $5 \%$ and a power of $80 \%$. Thus, allowing for a $7 \%$ dropout rate, a minimum of 30 patients per group was required.

After operating with long-segment instrumentation (two levels above and below the injured level or two levels above and one level below with using a pedicle screw at the fractured level), instrumented stabilization was achieved using pedicle screw fixation (Zenius; Medyssey, Jecheon, Korea) without decompression (Figs. 1, 2). Posterior spinal fusion was performed using an autologous local bone graft. The operations were performed by a single surgeon (W.S.).

At the end of the fusion operation, and after the spinal fascia was closed, an appropriate solution was injected into the posterior surface of the decorticated laminae via the drain tube (Redon-Drain; Pfm Medical Mepro $\mathrm{GmbH}$, Nonnweiler-Otzenhausen, Germany). In patients receiving topical TXA, the solution containing $1 \mathrm{~g}$ of TXA (Transamin; OLIC Thailand, Ayutthaya, Thailand), yielding a total volume of $20 \mathrm{~mL}(250 \mathrm{mg} / 5 \mathrm{~mL})$, was applied to the site of surgery. The drain bottle was then connected
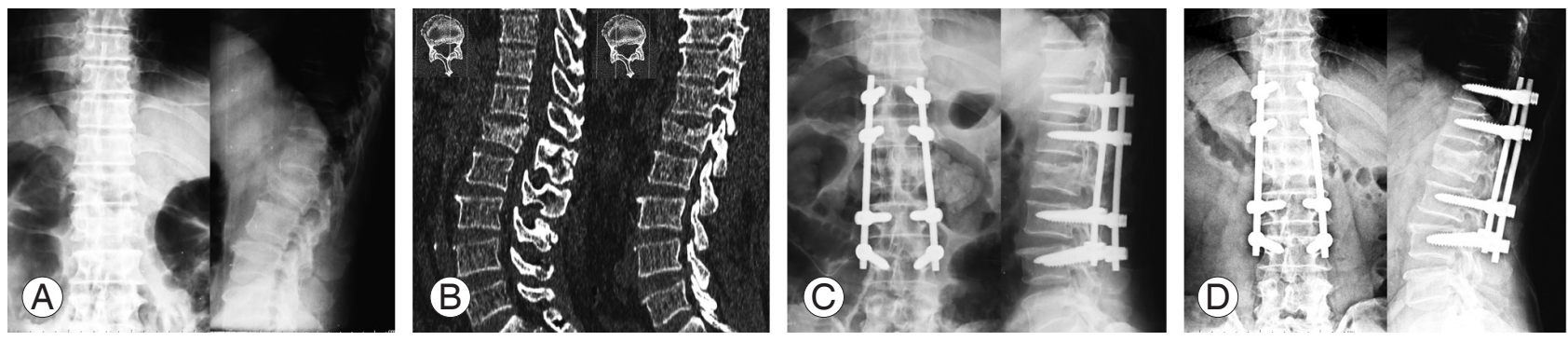

Fig. 1. A 64-year-old man fell from a height of $3 \mathrm{~m}$ in a building and complained of severe back pain at the thoracolumbar junction. (A) Preoperative plain film demonstrated a burst fracture of L1. (B) Sagittal computed tomography reconstruction showed a spinous process fracture on L1 and a slight widening of the facet joints (T12-L1 and L1-L2), which confirmed the diagnosis of posterior ligamentous complex involvement. (C) Postoperative plain film of the thoracolumbar spine depicting pedicle screw fixation T11-L3. (D) Well-maintained sagittal alignment at 1-year follow-up.
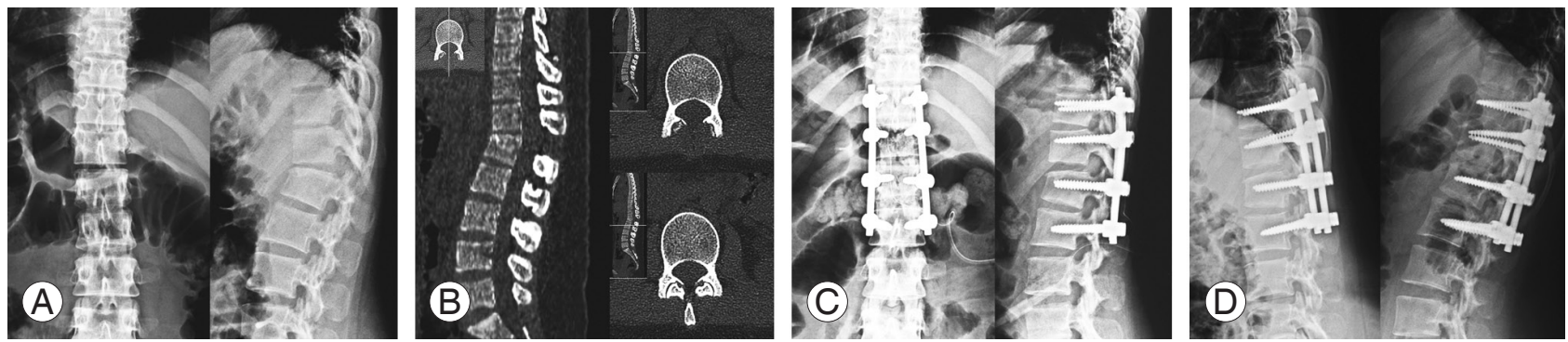

Fig. 2. A 24-year-old woman was injured in a motor vehicle accident. On admission, the patient was neurologically intact. (A) Preoperative plain film showed a flexion-distraction injury at T12-L1 and mild superior endplate fracture of L1. (B) Axial computed tomography scan showed empty facet joints. (C) Postoperative plain film detailing a pedicle screw-instrumented spine at T11-L2. (D) Flexion and extension radiographs 1 year after the injury show satisfactory alignment. 
to the drain tube, which was clamped for 2 hours. The same volume of normal saline was given to the control group, and clamping was performed using the same technique as in the experimental group. A research anesthesiologist nurse prepared the treatment medications and placebo, which were identical in appearance. Even after application of the experimental solution, the investigators did not know the group assignments.

The same postoperative protocols were followed in each group except for drainage tube removal. The drain was removed at no more than 5 days after the surgical procedure or when the drainage output had been less than $50 \mathrm{~mL}$ for the previous 24 hours. A complete blood count was performed at 2, 24, and 48 hours postoperatively. Symptoms (such as fatigue, headache, or dizziness) and signs (such as tachycardia, conjunctival pallor, shortness of breath, or tachypnea) of declining hemoglobin $(\mathrm{Hb})$ levels were assessed and used as an adjunct to laboratory abnormalities.

The primary outcome was requirement for PRC transfusion postoperatively prior to discharge home. The transfusion criteria followed the clinical practice guideline recommending transfusion if postoperative $\mathrm{Hb}$ was $\leq 8 \mathrm{~g} / \mathrm{dL}$ or postoperative $\mathrm{Hb}$ was $<10 \mathrm{~g} / \mathrm{dL}$ with anemic symptoms [14]. The secondary outcomes were total drainage volume, time to drain removal, and duration of postoperative hospitalization. Severity of pain was assessed using Visual Analog Scale (VAS). Data on adverse events, complications, and their effect on spinal fusion were also collected in the early postoperative course and during a follow-up period of at least 12 months.

\section{Ethical approval and consent to participate}

Ethics approval was obtained from the Institutional Review Board, Maharat Nakhon Ratchasima Hospital Ethics Committee (IRB approval no., MNRH IRB 102/2015). All participants provided informed consent. The study was retrospectively registered at Clinicaltrials.in.th (Identifier: TCTR20160412001) on April 11, 2016.

\section{Statistical analysis}

All statistical analyses were conducted using IBM SPSS software for Windows ver. 23.0 (IBM Corp., Armonk, NY,

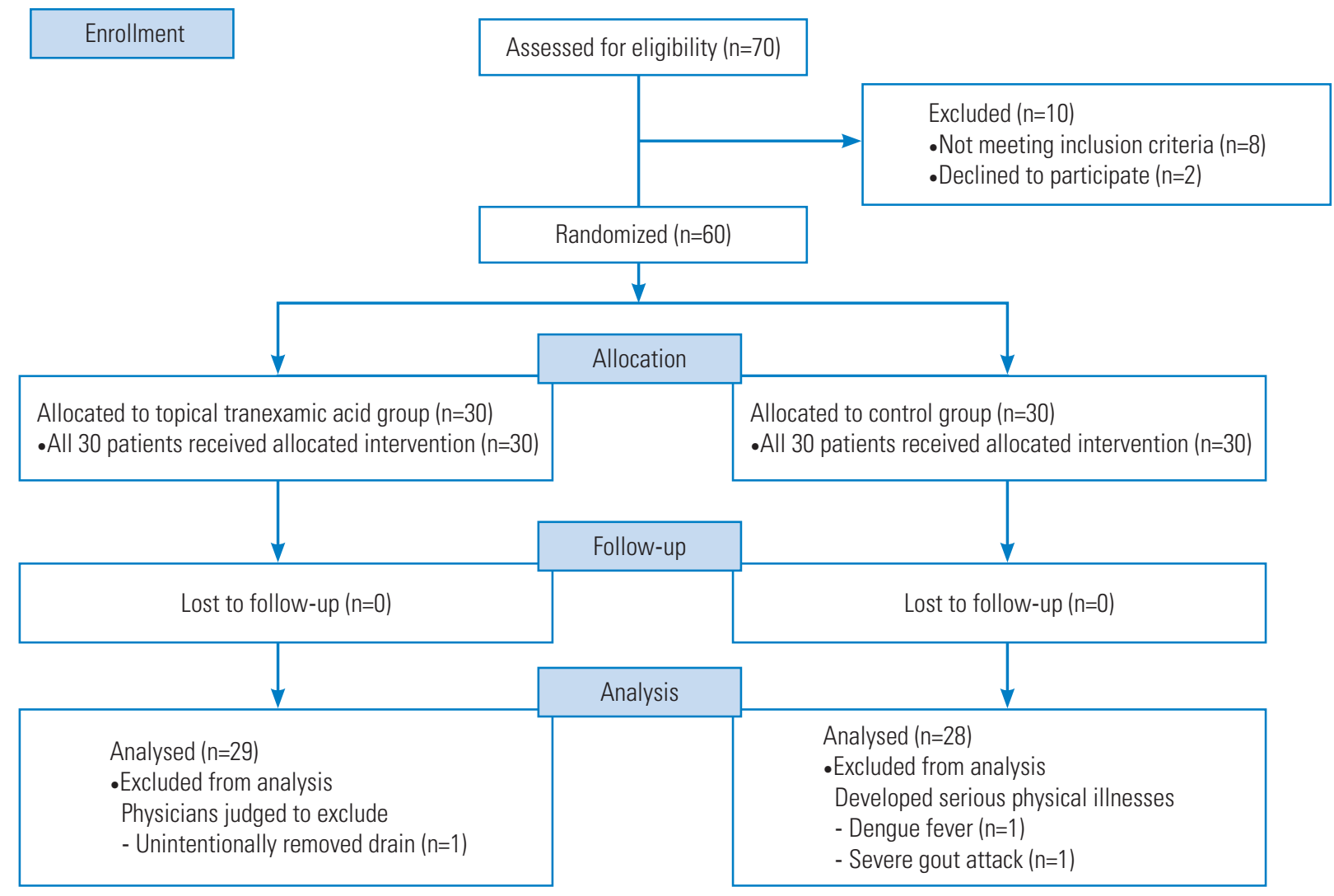

Fig. 3. Consolidated standards of reporting trials flow diagram showing the progress of study participants throughout the trial. 
USA). Variables were expressed as medians and interquartile ranges (IQR), frequencies and percentages, or means and standard deviations, as appropriate. The nonparametric Mann-Whitney $U$-test was used for non-normally distributed data. The chi-square test was used for testing relationships between categorical variables to examine proportional differences. The two-sample $t$-test was performed to examine mean differences between groups. The proportions of patients who received PRC transfusions are summarized as percentages, and $95 \%$ confidence intervals (CI) are specified. A $p$-value $<0.05$ was considered to indicate statistical significance.

\section{Results}

Sixty participants were recruited and randomized to receive the study medication or placebo. The study group comprised 57 patients, including 29 in the topical TXA group and 28 in the control group (Fig. 3). Three participants dropped out for health reasons $(\mathrm{n}=2)$ or an adverse event unrelated to the treatment $(n=1)$. Two patients in the control group developed severe physical illnesses that were judged to be incompatible with the study aims, and one patient in the topical TXA group was excluded because of an unintentionally removed drain (day 1 ). The groups were similar at baseline (Table 2).

Table 2. General baseline characteristics $(n=57)$

\begin{tabular}{|c|c|c|c|}
\hline Characteristic & Topical tranexamic acid group (n=29) & Control group $(\mathrm{n}=28)$ & $p$-value \\
\hline Age (yr) & $52(33.5-55.5)$ & $51.5(33.5-58.0)$ & $0.45^{\text {a) }}$ \\
\hline Sex & & & $0.23^{b)}$ \\
\hline Male & $20(69.1)$ & $15(53.6)$ & \\
\hline Female & $9(30.9)$ & $13(46.4)$ & \\
\hline Body mass index $\left(\mathrm{kg} / \mathrm{m}^{2}\right)$ & $22.2 \pm 3.3$ & $22.3 \pm 3.2$ & $0.87^{c)}$ \\
\hline Thoracolumbar Injury Classification and Severity score & & & $0.12^{b)}$ \\
\hline 5 & $21(72.4)$ & $26(92.9)$ & \\
\hline 6 & $1(3.5)$ & - & \\
\hline 7 & $7(24.1)$ & $2(7.1)$ & \\
\hline Mechanism of injury & & & $0.98^{b)}$ \\
\hline Fall from height & $20(69.0)$ & $18(64.3)$ & \\
\hline Motorcycle accident & $4(13.8)$ & $4(14.2)$ & \\
\hline Motor vehicle accident & $4(13.8)$ & $5(17.9)$ & \\
\hline Stuck by a heavy object & $1(3.4)$ & $1(3.6)$ & \\
\hline Fractured level & & & $0.29^{b)}$ \\
\hline T11 & $3(10.3)$ & $1(3.6)$ & \\
\hline $\mathrm{T} 12$ & $8(27.6)$ & $5(17.9)$ & \\
\hline L1 & $16(55.2)$ & $16(57.1)$ & \\
\hline L2 & $2(6.9)$ & $6(21.4)$ & \\
\hline American Society of Anesthesiologists physical status & & & $0.56^{b)}$ \\
\hline 1 or 2 & $22(75.9)$ & $23(82.1)$ & \\
\hline 3 & $7(24.1)$ & $5(17.9)$ & \\
\hline Preoperative anterior body height loss (\%) & $49.4 \pm 14.3$ & $46.0 \pm 13.0$ & $0.36^{c l}$ \\
\hline Fracture body angle $\left({ }^{\circ}\right)$ & $19.9 \pm 6.1$ & $20.2 \pm 8.3$ & $0.89^{c l}$ \\
\hline Operative time (min) & $98.6 \pm 18.2$ & $91.0 \pm 18.6$ & $0.12^{c)}$ \\
\hline Intraoperative fluid volume (mL) & $1,753.5 \pm 365.5$ & $1,882.1 \pm 434.5$ & $0.23^{c)}$ \\
\hline Intraoperative total estimated blood loss (mL) & $260.3 \pm 166.0$ & $265.0 \pm 146.6$ & $0.90^{c)}$ \\
\hline
\end{tabular}

Values are presented as median (interquartile range), number (\%), or mean \pm standard deviation.

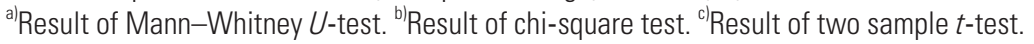


No differences were found in preoperative and intraoperative transfusion rates between the topical TXA group and the control group (20.7\% versus $17.9 \%$; $95 \% \mathrm{CI}, 0.40$ to $3.69 ; p=0.79$ and $13.8 \%$ versus $25.0 \%$; $95 \% \mathrm{CI}, 0.18$ to $1.68 ; p=0.28$, respectively). The rate of postoperative PRC transfusion was significantly lower in the topical TXA group than in the control group (13.8\% versus $39.3 \%$; relative risk, $0.35 ; 95 \% \mathrm{CI}, 0.13$ to $0.97 ; p=0.03$ ).

The mean total drainage volume was significantly less in the topical TXA group than in the control group $(246.7 \pm 125 \mathrm{~mL}$ versus $445.7 \pm 211.1 \mathrm{~mL}, p<0.01)$. The median drainage output during the first 24 hours and the subsequent 24 - to 48 -hour and 48 - to 72 -hour periods was also significantly less in the topical TXA group than in the control group $(200 \mathrm{~mL}$ versus $315 \mathrm{~mL}$; IQR, 100-250 $\mathrm{mL}$ versus $215-407.5 \mathrm{~mL} ; p<0.01 ; 50 \mathrm{~mL}$ versus $75 \mathrm{~mL}$; IQR, $20-90 \mathrm{~mL}$ versus $52.5-107.5 \mathrm{~mL} ; p=0.02$, and $0 \mathrm{~mL}$ versus $5 \mathrm{~mL}$; IQR, $0-5 \mathrm{~mL}$ versus $0-37.5 \mathrm{~mL} ; p=0.02$, respectively) (Fig. 4). No difference was found in the mean preoperative $\mathrm{Hb}$ level on the day of operation between the topical TXA group and the control group $(12.5 \pm 1.7 \mathrm{~g} /$ $\mathrm{dL}$ versus $11.9 \pm 1.5 \mathrm{~g} / \mathrm{dL}$; range, $8-15 \mathrm{~g} / \mathrm{dL}$ versus $7.5-15$ $\mathrm{g} / \mathrm{dL} ; p=0.16$ ), but the topical TXA group had higher mean $\mathrm{Hb}$ levels than the control group (patients who had received a postoperative transfusion were not included in the analysis) at 2, 24, and 48 hours postoperatively $(12.2 \pm 1.8 \mathrm{~g} / \mathrm{dL}$ versus $11.2 \pm 1.6 \mathrm{~g} / \mathrm{dL}$; range, $8-15 \mathrm{~g} / \mathrm{dL}$ versus $7.9-15 \mathrm{~g} / \mathrm{dL} ; p=0.04 ; 11.7 \pm 1.5 \mathrm{~g} / \mathrm{dL}$ versus $10.6 \pm 1.5$ $\mathrm{g} / \mathrm{dL}$; range, $9-14.9 \mathrm{~g} / \mathrm{dL}$ versus $7.6-13.8 \mathrm{~g} / \mathrm{dL} ; p=0.01$,

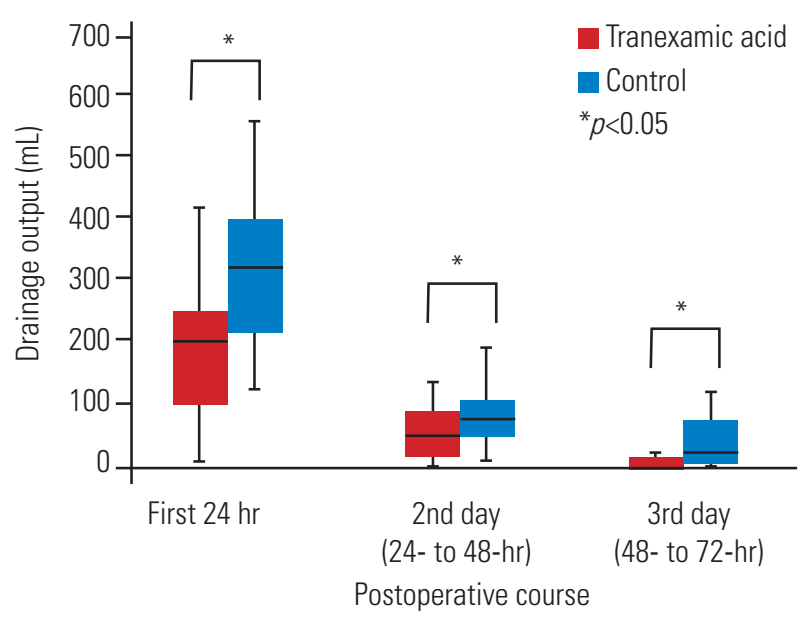

Fig. 4. Median and interquartile range of drainage output during the first 24 hours and the subsequent 24- to 48-hour and 48- to 72-hour periods after operation.

Table 3. Results of the data analysis for length of stay, time from injury to surgery, drain removal time, radiographic parameters, postoperative blood loss, VAS scores and follow-up duration between the topical TXA and the control group

\begin{tabular}{|c|c|c|c|}
\hline Variable & Topical TXA group (n=29) & Control group $(n=28)$ & $p$-value \\
\hline Length of stay (day) & $12.9 \pm 5.1$ & $17.3 \pm 6.5$ & $0.00^{a)}$ \\
\hline Time from injury to surgery (day) & $5.2 \pm 3.6$ & $6.8 \pm 3.5$ & $0.09^{a)}$ \\
\hline Postoperative hospitalization (day) & $7.7 \pm 2.7$ & $10.4 \pm 6.2$ & $0.03^{\mathrm{a})}$ \\
\hline Drain removal time (day) & $2.8 \pm 0.9$ & $3.2 \pm 0.8$ & $0.04^{a)}$ \\
\hline Postoperative anterior body height loss (\%) & $17.3 \pm 10.6$ & $15.5 \pm 12.7$ & $0.57^{\mathrm{a})}$ \\
\hline Postoperative fracture body angle $\left({ }^{\circ}\right)$ & $10.2 \pm 4.8$ & $9.1 \pm 5.2$ & $0.43^{\text {a) }}$ \\
\hline \multicolumn{4}{|l|}{ Postoperative blood loss (mL) } \\
\hline Dressing gauze blood loss & $32.2 \pm 26.9$ & $43 \pm 28.1$ & $0.14^{a)}$ \\
\hline Drainage blood loss & $246.7 \pm 125$ & $445.7 \pm 211.1$ & $0.00^{a)}$ \\
\hline Total blood loss & $279 \pm 135.2$ & $488.8 \pm 223.5$ & $0.00^{a)}$ \\
\hline \multicolumn{4}{|l|}{ VAS } \\
\hline VAS at $24 \mathrm{hr}$ before operation & $5(4-5)$ & $5(4-6)$ & $0.52^{b)}$ \\
\hline VAS at $24 \mathrm{hr}$ after operation & $7(6.5-8)$ & $7(7-8)$ & $0.80^{\mathrm{bl}}$ \\
\hline VAS at $48 \mathrm{hr}$ after operation & $6(5-8)$ & $5.5(5-7)$ & $0.23^{b)}$ \\
\hline VAS at discharge from hospital & $3(2-5)$ & $3.5(3-5.8)$ & $0.67^{b)}$ \\
\hline Follow-up duration (mo) & $28.1 \pm 4.6$ & $26.9 \pm 4.7$ & $0.36^{b l}$ \\
\hline
\end{tabular}

Values are presented as mean \pm standard deviation or median (interquartile range). Bold type is considered statistically significant $(p<0.05)$. VAS, Visual Analog Scale; TXA, tranexamic acid.

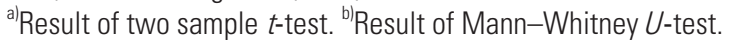


and $11.6 \pm 1.3 \mathrm{~g} / \mathrm{dL}$ versus $10.7 \pm 1.2 \mathrm{~g} / \mathrm{dL}$; range, $9-14.5 \mathrm{~g} /$ $\mathrm{dL}$ versus $7.8-13.3 \mathrm{~g} / \mathrm{dL} ; p=0.04$, respectively). The mean number of days to drain removal in the topical TXA group was $2.8 \pm 0.9$ days, compared with $3.2 \pm 0.8$ days in the control group, a significant difference $(p=0.04)$. The mean duration of postoperative hospitalization was significantly shorter in the topical TXA group than in the control group ( $7.7 \pm 2.7$ days versus $10.4 \pm 6.2$ days, $p=0.03$ ). The difference between the two groups in pain score, as measured by VAS preoperatively and at any time period postoperatively, was nonsignificant (all $p>0.05$ ) (Table 3 ).

Posterior fusion was achieved within 12 months in all cases, and there was no failure of instrumentation according to radiographs during an average follow-up of 27.5 \pm 4.7 months (range, 20.3 to 35.6 months). Regarding the safety outcome, the investigators found no clinical evidence of adverse events or complications up to 1 year following the procedure.

\section{Discussion}

The currently available clinical data confirm that intravenous TXA during spinal surgery can reduce perioperative bleeding, but the evidence to reach a reliable conclusion regarding safety risk so far is too limited $[8-10,15,16]$. Myocardial infarction and systemic thromboembolic complications are rare but potentially life-threatening events in surgical patients receiving intravenous TXA [11]. The theoretical concern for the risk of thromboembolism with intravenous TXA remains, which has encouraged investigations on TXA administration via a topical route.

In the field of cardiac and arthroplasty surgery, topical TXA has been introduced as an equally effective and safe alternative to intravenous TXA, especially for the prevention of postoperative bleeding events $[11,12]$. The mechanism of topical application of TXA, a synthetic derivative of the amino acid lysine that has strong antifibrinolytic activity, is through binding to the bleeding surface, which is believed to inhibit local fibrinolysis only at the surgical field. TXA can block the enzymatic interaction of plasminogen/plasmin with fibrinogen/fibrin, thereby preventing fibrin degradation and delaying clot dissolution [17].

Some trials have reported on the effect of topical TXA in spinal procedures. Krohn et al. [18] reported that 500 $\mathrm{mg}$ of TXA added to the irrigation solution and suctioned away after 2 to 5 minutes of application significantly reduced blood loss in lumbar spinal fusion surgery by up to half. Similarly, Saberi et al. [19] found that locally poured $250 \mathrm{mg}$ of TXA, with a volume of $5 \mathrm{~mL}$, in the epidural space of patients undergoing laminectomy significantly reduced postoperative drainage volume on the first and second days, as well as overall. The use of topical TXA in spine surgery has recently been reviewed in a meta-analysis [20] of four studies of 136 patients who received TXA via an irrigation solution or a soaked absorbable gelatin sponge compared with 134 patients who received saline placebo. Luo et al. [20] reported that topical TXA reduced postoperative drain output (mean difference, -157 $\mathrm{mL} ; p<0.01$ ) and transfusion risk (risk difference, -0.18 ; $p=0.28$ ). The authors of the present study tried to apply a different technique for the use of topical TXA in posterior spinal fusion surgery and obtained favorable outcomes, especially in a multilevel procedure without laminectomy (mean difference in drain output, $-199 \mathrm{~mL} ; p<0.01$; risk difference for transfusion, $-0.26 ; p=0.03$ ).

The optimal dose of TXA for reduction of postoperative blood loss has not yet been established. Previous studies showed that topical application of $500 \mathrm{mg}$ to $3 \mathrm{~g}$ of TXA reduced postoperative or total blood loss compared with placebo in patients undergoing total knee arthroplasty [21-23]. Ker et al. [9] examined the data from 104 studies and found that various doses of intravenous TXA administered in randomized controlled trials had a significant effect on the amounts of intraoperative and postoperative blood loss. The reported doses of TXA in 18 randomized controlled trials ( $\mathrm{n}=1,651$ patients) were highly heterogeneous, ranging from 5.5 to $300 \mathrm{mg} / \mathrm{kg}$. A dose of $1 \mathrm{~g}$ appeared to be sufficient for most adults, whereas no evidence emerged to support the use of high doses of TXA [9]. As reported in patients undergoing cardiac surgery, Martin et al. [24] noted that the use of high-dose TXA resulted in seizure rates that were at least 10 -fold higher than those seen with low-dose administration. Concern about safety led the authors of the present study to undertake research using a moderate dose of TXA. However, a 1 -g dose was sufficient in a four-level spinal fusion procedure, as demonstrated by the results of the present study.

The ideal technique for topical use and the optimal timing of intraoperative topical TXA application in spinal surgery have not been clearly determined. According to the pharmacodynamic and pharmacokinetic properties of TXA, the maximum plasma concentration is obtained at 30 minutes after administration, and the terminal elimination half-life is about 120 minutes [17]. In the present 
study, $1 \mathrm{~g}$ of topical TXA was applied to the site of surgery via a drain tube after the spinal fascia was closed, and then the drain was clamped for 2 hours. The length of time that the drain was clamped was equal to the half-life of TXA and was sufficient for the hemostatic activity of topical TXA to be exerted before the drain was unclamped. A longer clamping period might cause more pain and might predispose to the formation of large hematomas, which sometimes require surgical removal.

The authors decided to exclude patients from the study who had neurological deficits that required decompressive surgery, for the following reasons. First, caution needs to be taken to prevent direct contact between TXA and neural tissues, because epileptic seizures were reported to develop when TXA was topically applied for surgery within or close to the central nervous system in an experimental rat model [25]. Second, an association between dural tears and neurological deficits has been consistently reported in patients with spinal injuries [26-28]. For these reasons, the use of topical TXA poses a considerable risk in patients presenting with neurological deficits resulting from TLST.

There were some limitations to the present study. The extent of topical TXA tissue absorption following clamping of the drain was not quantified and should be documented by collecting samples, such as serum or plasma. Subsequent analysis of hemolytic activity should be conducted and the concentration of degradation products via the drainage tube should be measured to obtain further information about the mechanism of action and systemic absorption of topical TXA. Pulmonary arteriograms and lower extremity venograms are recommended to detect thromboembolism; however, in this study clinical assessment was used to detect complications because of the relatively high cost and invasiveness of these tools. An additional limitation of this study was the mid-term followup period (more than 1 year but less than 5 years), which is inadequate to monitor potential long-term complications.

\section{Conclusions}

The use of topically administered $1 \mathrm{~g}$ of TXA $(20 \mathrm{~mL})$ in thoracic and lumbar spinal trauma cases undergoing a posterior fusion procedure with long-segment instrumentation effectively decreased postoperative transfusion requirements. The treatment also reduced total drainage volume, time until drain removal, and length of postop- erative hospital stay.

\section{Conflict of Interest}

No potential conflict of interest relevant to this article was reported.

\section{ORCID}

Weera Sudprasert: https://orcid.org/0000-0003-0697-8053

Terdpong Tanaviriyachai: https://orcid.org/0000-0002-6587-0344

Kongtush Choovongkomol: https://orcid.org/0000-0002-6999-4547

Sarut Jongkittanakul: https://orcid.org/0000-0002-5459-0953

Urawit Piyapromdee: https://orcid.org/0000-0002-8451-5989

\section{References}

1. Glennie RA, Ailon T, Yang K, et al. Incidence, impact, and risk factors of adverse events in thoracic and lumbar spine fractures: an ambispective cohort analysis of 390 patients. Spine J 2015;15:629-37.

2. Rajasekaran S, Kanna RM, Shetty AP. Management of thoracolumbar spine trauma: an overview. Indian J Orthop 2015;49:72-82.

3. Joaquim AF, Fernandes YB, Cavalcante RA, Fragoso RM, Honorato DC, Patel AA. Evaluation of the thoracolumbar injury classification system in thoracic and lumbar spinal trauma. Spine (Phila Pa 1976) 2011;36:33-6.

4. Azhari S, Azimi P, Shahzadi S, Mohammadi HR, Khayat Kashani HR. Decision-making process in patients with thoracolumbar and lumbar burst fractures with thoracolumbar injury severity and classification score less than four. Asian Spine J 2016;10:136-42.

5. Tse EY, Cheung WY, Ng KF, Luk KD. Reducing perioperative blood loss and allogeneic blood transfusion in patients undergoing major spine surgery. J Bone Joint Surg Am 2011;93:1268-77.

6. Marik PE, Corwin HL. Efficacy of red blood cell transfusion in the critically ill: a systematic review of the literature. Crit Care Med 2008;36:2667-74.

7. Elgafy H, Bransford RJ, McGuire RA, Dettori JR, Fischer D. Blood loss in major spine surgery: are there effective measures to decrease massive hemorrhage in major spine fusion surgery? Spine (Phila $\mathrm{Pa}$ 1976) 2010;35(9 Suppl):S47-56.

8. Hofmann A, Ozawa S, Farrugia A, Farmer SL, 
Shander A. Economic considerations on transfusion medicine and patient blood management. Best Pract Res Clin Anaesthesiol 2013;27:59-68.

9. Ker K, Prieto-Merino D, Roberts I. Systematic review, meta-analysis and meta-regression of the effect of tranexamic acid on surgical blood loss. Br J Surg 2013;100:1271-9.

10. Badeaux J, Hawley D. A systematic review of the effectiveness of intravenous tranexamic acid administration in managing perioperative blood loss in patients undergoing spine surgery. J Perianesth Nurs 2014;29:459-65.

11. Ker K, Edwards P, Perel P, Shakur H, Roberts I. Effect of tranexamic acid on surgical bleeding: systematic review and cumulative meta-analysis. BMJ 2012;344:e3054.

12. Winter SF, Santaguida C, Wong J, Fehlings MG. Systemic and topical use of tranexamic acid in spinal surgery: a systematic review. Global Spine J 2016;6:284-95.

13. Sudprasert W, Tanaviriyachai T, Choovongkomol K, Jongkittanakul S, Piyapromdee U. Topical tranexamic acid reduces postoperative blood loss in posterior spinal fusion with instrumentation: a retrospective clinical study of patients with thoracolumbar spinal injury. J Med Assoc Thai 2018;101(3 Suppl):S15-22

14. Carson JL, Grossman BJ, Kleinman S, et al. Red blood cell transfusion: a clinical practice guideline from the AABB. Ann Intern Med 2012;157:49-58.

15. Yang B, Li H, Wang D, He X, Zhang C, Yang P. Systematic review and meta-analysis of perioperative intravenous tranexamic acid use in spinal surgery. PLoS One 2013;8:e55436.

16. Cheriyan T, Maier SP 2nd, Bianco K, et al. Efficacy of tranexamic acid on surgical bleeding in spine surgery: a meta-analysis. Spine J 2015;15:752-61.

17. McCormack PL. Tranexamic acid: a review of its use in the treatment of hyperfibrinolysis. Drugs 2012;72:585-617.

18. Krohn CD, Sorensen R, Lange JE, Riise R, Bjornsen $\mathrm{S}$, Brosstad F. Tranexamic acid given into the wound reduces postoperative blood loss by half in major orthopaedic surgery. Eur J Surg Suppl 2003;(588):5761.
19. Saberi H, Miri SM, Namdar MP. The effects of topically applied tranexamic acid on reduction of postlaminectomy hemorrhage. Tehran Univ Med J 2010;68;527-33.

20. Luo W, Sun RX, Jiang H, Ma XL. The efficacy and safety of topical administration of tranexamic acid in spine surgery: a meta-analysis. J Orthop Surg Res 2018;13:96.

21. Wong J, Abrishami A, El Beheiry H, et al. Topical application of tranexamic acid reduces postoperative blood loss in total knee arthroplasty: a randomized, controlled trial. J Bone Joint Surg Am 2010;92:250313.

22. Ishida K, Tsumura N, Kitagawa A, et al. Intra-articular injection of tranexamic acid reduces not only blood loss but also knee joint swelling after total knee arthroplasty. Int Orthop 2011;35:1639-45.

23. Sa-Ngasoongsong P, Wongsak S, Chanplakorn P, et al. Efficacy of low-dose intra-articular tranexamic acid in total knee replacement; a prospective tripleblinded randomized controlled trial. BMC Musculoskelet Disord 2013;14:340.

24. Martin K, Wiesner G, Breuer T, Lange R, Tassani P. The risks of aprotinin and tranexamic acid in cardiac surgery: a one-year follow-up of 1188 consecutive patients. Anesth Analg 2008;107:1783-90.

25. Schlag MG, Hopf R, Zifko U, Redl H. Epileptic seizures following cortical application of fibrin sealants containing tranexamic acid in rats. Acta Neurochir (Wien) 2002;144:63-9.

26. Park JK, Park JW, Cho DC, Sung JK. Predictable factors for dural tears in lumbar burst fractures with vertical laminar fractures. J Korean Neurosurg Soc 2011;50:11-6.

27. Luszczyk MJ, Blaisdell GY, Wiater BP, et al. Traumatic dural tears: what do we know and are they a problem? Spine J 2014;14:49-56.

28. Skiak E, Karakasli A, Harb A, Satoglu IS, Basci O, Havitcioglu H. The effect of laminae lesion on thoraco-lumbar fracture reduction. Orthop Traumatol Surg Res 2015;101:489-94. 